American Journal of Geosciences 2 (1): 1-3, 2011

ISSN 1948-9846

(C) 2011 Science Publications

\title{
Advantages of Utilizing Geotextiles in Fixing Sandy Soils and Increasing Shear Strength in Water Conveyance Trenches
}

\author{
${ }^{1}$ Alireza Mardookhpour and ${ }^{2}$ Leila Ooshaksaraie \\ ${ }^{1}$ Department of Civil and Water Engineering, \\ ${ }^{2}$ Department of Environmental Engineering, \\ Islamic Azad University, Lahijan Branch, PO Box, 1616, Iran
}

\begin{abstract}
With the increasing demand in water supply and either for generation or for irrigation and human consumption, water conveyance structures must guarantee a maximum efficiency at the lowest construction and maintenance costs. Using thin geotextiles allow very low permeability and very high transmissivity. Conclusion/Recommendations: The system constructs a continues, low roughness on the entire section of canal. In this research study the use of geotextile in order to stabilize and increase in shear strength of sandy soils has been investigated. The results show an increase about $44 \%$ of shear strength that cause an enhancement of stability of soils.
\end{abstract}

Key words: Conveyance structures, geotextile, stabilize, shear strength

\section{INTRODUCTION}

In conveyance structures, efficiency is measured on the amount of water transported in safety conditions, which must be as close as possible to the amount of inlet water. Impermeable and light weight materials such as polymer materials especially geotextiles, with low hydraulic roughness, used in proper section and slope, provide an efficient design. Moreover, over time, operation of the canal changes the design performance, due to the action of water and the environment on a structure which is subjected to ageing. Ageing results in: (a) Water losses (b) Reduction in water flow (c) Structure deterioration and (d) Detachment of lining materials. Generally, in adequate strength of soil and movement of soil particles by water flow cause low tensile strength of soil materials. One of the modern methods in strengthening soils is utilizing polymer materials. This method has several advantages over traditional ones. At the beginning of reinforcing sandy soils, utilizing strip reinforcement, such as aluminum and galvanized steel were introduced but its consumption decreased due to corrosion factor of these substances. There are several technical-economical and marketing reasons for development of polymer materials (Ingold and Miller, 1982). These reasons are:

- Being manufactured in a factory under quality control procedures assuring constant and controllable quality
- Polymer materials can be installed rapidly

- Polymer materials can generally be installed in difficult environment conditions

- Their light weight and small volume results in easier and less expensive transport

- Polymer materials are generally cost- effective as compared to natural or traditional man-made materials

In this study detachment of lining materials and the ways of retrofitting of canals by polymer materials is discussed.

When the original linings are made with an unsuitable adherent material, ageing can result in detachment of the liner which can be caused by uplift exerted by water impregnating the natural slopes, by action of frost and vapor trapped behind a glued liner or by improper anchorage. Generally rehabilitation can be made with traditional liners such as concrete, gunite, metal sheets and bituminous membranes or with synthetic geomembranes. Each of discussed materials has some advantages and disadvantages that are as follows.

Concrete layer: It is suitable from the point of view of mechanical resistance and durability or long- lasting performance, but construction of a new layer reduces the canal cross section significantly that decrease water flow. Also installation is costly and time consuming

Corresponding Author: Alireza Mardookhpour, Department of Civil and Water Engineering, Islamic Azad University, Lahijan Branch, P.O. Box, 1616, Iran Tel: 0098211992399 
and the new concrete layer have the same problems such as joints, cracking and permeability.

Gunite: It is not so water tightness and requires long subgrade preparation. Also it has hydraulic roughness and low resistance to dynamic forces, uplifts and frost.

Metal sheets: They need more expensive and complicated installation and have high risk of corrosion.

Bituminous membranes: They require careful preparation of the subgrade, have low resistance to dynamic forces and uplifts, are dependent upon atmospheric conditions and have short durability.

Synthetic membranes: They are a viable option and provide a continues, low roughness bridging all construction joints and existing fissures. Geotextiles are from family of geosynthetics. Geosynthetics are textiles or some polymer material that their main properties are stability against deterioration factors which exist in soils or water (Saran, 2010). Geotextiles are commonly divided in to two groups: (a) Woven (b) Non-woven. Non-woven geotextiles are used to the address of reinforcement in our research experiments.

When geotextiles are employed as reinforcement the major properties are Young's modulus, tensile strength and strain in failure point (Mardookhpour, 2004; Noorzad, 2000; Scuero, 2004). Because of the sloping of the roof and the presence of a drainage system, the hydrostatic head acting on the polymer materials is in all conditions minimum (Ghiassian and Jahannia, 2004; Saxena, 2004). In conclusion the main concern when using a polymer material in roofing is the perfect welding of adjoining sheets and extension of placing. (Due to having holes, water coming from the inside of the structure (seepage), or migrating towards the canal from the surrounding can be drained and pore water pressure would not be produced) (Mardookhpour, 2003) US EPA 1996. Drainage capability assures that the liner is protected from uplifts and that soil stability is improved by the rehabilitation. Drainage occurs in the gap provided behind the liner and can be facilitated by installation of synthetic materials providing transmissivity. Highly transmissive geotextiles have been installed under the waterproofing liner on the bottom of the canal or over its whole cross section. Continuous and immediate discharge of drained water avoids its build-up behind membrane, therefore eliminating detachment problems. Water migrating towards the canal is continuously caught and moisture is subtracted from the soil. This feature can be of particular interest in case of canals excavated in steep unstable slopes.

The extension of setting geotextile is on the base of Columb formula Eq. 1:

$\tau=\mathrm{c}+\sigma \times \operatorname{tg} \varphi$

Where:

$\tau=$ Shear strength of soil

$\mathrm{c}=$ Cohesive strength of soil

$\sigma=$ Effective stress on soil

$\varphi=$ The angle of internal friction of soil particles

According to the idea of the most designers, the best extension for placing reinforcements is in extension of major principal strain. leaning on before studies, in this research study, it is emphasized on special extension for placing reinforcement in sandy soils that would more increase the angle of internal friction of soils. Generally, the best extension for placing geotextile in sandy soils with gravels is the extension of principle strain in soil. In this case according to Columb formula the maximum shear strength in soil is obtained theoretically. For determining the best extension of placing geotextile in sandy soils with gravels some experiments have been done in soil mechanics laboratory.

According to the results of experiments if geotextile applied in $60^{\circ}$ to horizontal failure plane, the maximum shear strength is provided in soils. For example, for two sample of washed sandy soil with characteristics of $\mathrm{D}_{50}=5 \mathrm{~mm}$ and maximum dry density $\gamma_{\mathrm{d}}=2.08 \mathrm{~g} \mathrm{~cm}^{-3}$, subjected to equal effective loads, one of them reinforced by a tin layer of geotextile with $50 \mathrm{kn} \mathrm{m}^{-1}$ tensile strength, the increase of shear strength is Eq. 2:

Shear strength of soil before reinforcing:

$\rightarrow \tau_{1}=\sigma \times \operatorname{tg} 32^{\circ}$

Shear strength of soil after reinforcing by geotextile in $60^{\circ}$ to horizontal failure Eq. 3:

Plane with the same effective stress:

$\rightarrow \tau_{2}=\sigma \times \operatorname{tg} 42^{\circ}$ 
Am. J. Geoscience 2 (1): 1-3, 2011

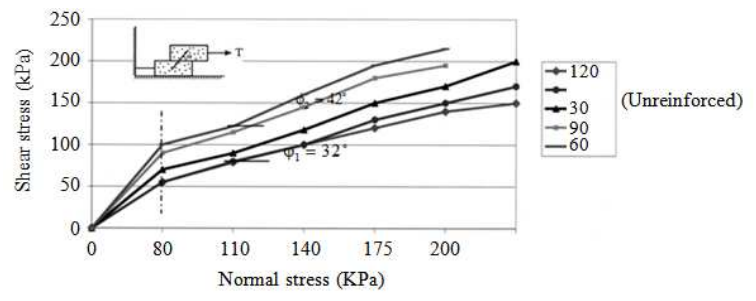

Fig. 1: Variation of shear strength of sandy soil reinforced by geotextile

So, the increase in shear strength is obtained Eq. 4:

$$
\frac{\tau_{2}-\tau_{1}}{\tau_{1}}=\frac{\sigma \times \tan 42^{\circ}-\sigma \times \tan 32^{\circ}}{\sigma \times \tan 32^{\circ}}=0.44
$$

In other words, the increase of shear strength is equal to $44 \%$ approximately (Fig. 1). Hence, it is recommended that for further stabilizing the lateral faces and bottom of canals, a thin layer of geotextile places in $60^{\circ}$ to horizontal failure plane. The basic role of geotextile is increasing the angle of internal friction in sandy soils. For soils tested in this research the angle of internal friction increased about $10^{\circ}$ (from $32-42^{\circ}$ ). In other next experiments, geotextiles was placed in the same sandy soil with equal properties in angles of 30 , 60,90 and $120^{\circ}$ to horizontal plane and direct shear tests were done. According to the results of experiments, the best extension of placing geotextile in sandy soil is $\alpha=60^{\circ}$ and under this situation the angle of internal friction increases from $32-42^{\circ}$.

\section{CONCLUSION}

It is observed during experiments that due to increasing shear strength of sandy soil reinforced by geotextile, the stability of soil in slopes increases. According to the results of experiments if geotextile applied in $60^{\circ}$ to horizontal failure plane, the maximum shear strength is provided in soils. By utilizing geotextile the angle of internal friction increases about $10^{\circ}$, which causes more stability in sandy soils. (It should be noted that the sandy soil has a low adhesiveness and also effective stress during experiments is equal.). Although the best extension of placing geotextile in sandy soil is $\alpha=60^{\circ}$ and under this situation the angle of internal friction increases from $32-42^{\circ}$. In this case according to Columb formula the maximum shear strength in soil is obtained. By reinforcement the particles of sand are prevented from movement by water flow thus less slide slope occurs .Also by utilizing geotextiles in conveyance structures less sediment is produced. So the efficiency of conveyance structures would be increased.

\section{ACKNOWLEDGEMENT}

This study supported by Islamic Azad University and writer wishes to thank for equipment and software, department of civil engineering Islamic Azad University of Lahijan-Iran.

\section{REFERENCES}

Ghiassian, H. and M. Jahannia, 2004. Influence of encapsulated geogrid-sand system on bearing capacity and settlement characteristics of reinforced clay. Int. J. Civil Eng., 2: 45-53.

Ingold, T.S. and K.S. Miller, 1982. Analytical and laboratory investigations of reinforced clay. Proceedings of the 2nd International Conference on Geotextiles, (ICG' 82), Las Vegas, pp: 587-592.

Mardookhpour, A.R, 2003. New design in minimum use of earth materials that will increase the safety factor of upper and lower slopes condition in earth dams, (utilizing the polymer material and connected plates). Ph.D. Thesis, Islamic Azad University of Science and Research branch of Tehran, Iran.

Mardookhpour, A.R., 2004. Application of geotextile in coastal area. Ministry of Power of Iran.

Noorzad, R., 2000. Behavior characteristics of geotextile reinforced sand Ph.D. Thesis, Sharif University, Iran.

Saran, S., 2010. Reinforced Soil and Its Engineering Applications. 2nd Edn., I. K. International Pvt. Ltd., New Delhi, ISBN: 9380578369, pp: 440.

Saxena, K., 2004. Geosynthetics in embankment, First seminar on application of geosynthetic in hydraulic structures. IRCOLD, 1: 23-27.

Scuero, M., 2004. Geomembrane in rehabilitation of canals, First Seminar on application of geosynthetic in hydraulic structure. IRCOLD. 